\title{
Efficacy and Patient-Reported Outcomes of a New Mometasone Cream Treating Atopic Eczema
}

\author{
Thomas Ruzicka $^{\mathrm{a}}$ Christoph Willers $^{\mathrm{b}}$ Walter Wigger-Albertic \\ ${ }^{a}$ Department of Dermatology and Allergology, Klinikum Innenstadt Munich, Munich, ${ }^{\mathrm{b}}$ Almirall Hermal GmbH, \\ Reinbek, and 'bioskin GmbH, Hamburg, Germany
}

\section{Key Words}

Mometasone furoate $\cdot$ Cream $\cdot$ Patient acceptance $\cdot$

Efficacy · Atopic eczema • Corneometry • Quality of life

\begin{abstract}
This double-blind controlled phase II study was conducted to compare a newly developed formulation of mometasone furoate with a water content of $33 \%$ (Monovo ${ }^{\circledR}$ Cream) and with a smooth consistency versus the commercially available fatty cream of mometasone furoate (Ecural ${ }^{\circledR}$ Fettcreme) in terms of efficacy, cosmetic properties, and patients' acceptance. In 20 patients with mild to moderate atopic eczema, the preparations were tested intraindividually in a randomized mode and in two comparable lesion areas. Both preparations were equally effective and well tolerated. Due to improved cosmetic properties, the new formulation was preferred by the patients when asked for preferential use. Quality of life could be improved by treating with both preparations.

Copyright $\odot 2012$ S. Karger AG, Basel
\end{abstract}

\section{Introduction}

Despite a number of shortcomings, topical corticosteroids are a mainstay in the treatment of atopic eczema (AE) and remain the recommended first-line therapy in the recent position paper of the European Academy of Dermatology and Venereology [1]. The choice of a topical steroid should be tailored to each patient regarding its potency, the vehicle, and the affected skin areas, but the season, environment, and the patient's preference should also be considered [2].

The class III topical corticosteroid mometasone furoate is characterized by high efficacy together with low systemic availability and is established in the topical treatment of a variety of corticosteroid responsive disorders. It is licensed as a spray to treat allergic rhinitis or asthma and as a lotion, cream, or ointment for dermal application in inflammatory skin diseases. Its high efficacy and rapid onset of action, together with a favorable risk benefit profile, make it one of the most widely used topical corticosteroids [3]. In inflammatory skin disorders, mometasone furoate has become a standard medication for topical treatment [3-6].

Besides the active ingredient, other excipients and properties of topical preparations, such as penetration enhancers, or its lipophilicity, contribute to the bioavailability of the active ingredient and thus its overall therapeutic efficacy.

For the appropriateness in everyday use, the cosmetic properties of a preparation must not be underestimated. Ease of application, spreadability, and rate of absorption strongly support the patients' adherence to treatment and thus contribute considerably to the clinical outcome [7].

\section{KARGER}

Fax +4161306 1234

E-Mail karger@karger.ch

www.karger.com
(C) 2012 S. Karger AG, Basel

$1660-5527 / 12 / 0256-0305 \$ 38.00 / 0$

Accessible online at:

www.karger.com/spp
Prof. Dr. Dr. h.c. Thomas Ruzicka

Department of Dermatology and Allergology, Ludwig Maximilian University Frauenlobstrasse 9-11

DE-80337 Munich (Germany)

Tel. +49895160 6001, E-Mail Thomas.Ruzicka@med.uni-muenchen.de 
In this study, we present clinical data of a newly developed oil-in-water cream with $0.1 \%$ mometasone furoate and a water content of $33 \%$ (Monovo ${ }^{\circledR} \mathrm{Cream}^{1}$, preparation 1). The developmental efforts had focused on the convenience of its texture, good spreadability, and rapid absorption to improve the patients' comfort and satisfaction while requiring a topical corticosteroid. A commercially available preparation with $0.1 \%$ mometasone furoate $\left(\right.$ Ecural $^{\circledR}$ Fettcreme ${ }^{2}$, preparation 2 ) with a marginal water content below $5 \%$ served as comparator.

The aim of this study was to demonstrate the clinical equivalence of both preparations in terms of efficacy and tolerability in mild to moderate $\mathrm{AE}$, and to compare the convenience of the products, as reflected by the patients' assessment. Patients' acceptance and overall satisfaction were quantified by means of two questionnaires, one reflecting the cosmetic properties of the products and the other skin-related quality of life (Dermatology Life Quality Index, DLQI).

\section{Patients, Materials and Methods}

The single-center phase II study was performed in a randomized, double-blind, controlled design. Evaluation of efficacy was based on an intraindividual comparison in two predefined, comparable test areas.

Overall, 20 male and female patients aged $\geq 18$ years were included. The major inclusion criterion was the presence of mild to moderate $\mathrm{AE}$ with at least two comparable lesional areas on opposite extremities (forearm or lower leg). The clinical condition of mild to moderate AE had been defined as a scoring of AE (SCORAD) of $\geq 5$, with an erythema score of $\geq 2$, and lichenification, dryness, and itching score of $\geq 1$ each, and an Erlangen Atopy score sum not less than 10 points. The difference in local score values in the treatment fields was not allowed to exceed the level of 3.

Patients who were eligible for study participation were required not to show any relevant findings suggestive of a concomitant disease. Female participants of childbearing age had to agree to use reliable contraception.

A written informed consent was obtained from all participants. The study was conducted in accordance with German Drug Law (Arzneimittelgesetz), the currently valid revision of the Helsinki Declaration, and the International Conference on Harmonisation Good Clinical Practice Guidelines (EudraCT-No. 2009-017407-28; NCT 01119313).

The treatment area was defined as the entire ventral forearm in case of lesions on the arm, or as the entire ventral lower leg in case of lesions on the leg. At least one lesional region within each

1 Scheduled brand name Monovo Cream, Almirall Hermal GmbH, Germany.

2 Ecural Fettcreme (international trade name Elocon ${ }^{\circledR}$ ), Schering-Plough (Merck Sharp and Dohme Ltd.). of these areas had to cover $\geq 20 \mathrm{~cm}^{2}$. Areas between 100 and 300 $\mathrm{cm}^{2}$ per patient were subject to evaluation.

Each predefined area was treated with $2 \mathrm{mg} / \mathrm{cm}^{2}$ mometasone furoate, corresponding to an amount of 200-600 $\mu$ l of one of the test products (preparation 1 and preparation 2). The creams were applied once daily by the patients themselves at home; the treatment period was 2 weeks.

Adequate application was verified by weighing the returned amount of the product and by the records in a treatment diary. If a significant deviation from the estimated need was suspected at the visit on day 8 , the patient was advised to adjust the dose.

The patients were instructed to avoid activities causing excessive sweating, such as sunbathing, or visiting public swimming pools during the study period. Patients were not allowed to use additives such as bath or shower oils, or any cosmetic preparations, in the test areas.

The preparations were blinded and randomization was made by permutation of the treatment codes $\mathrm{A}$ and $\mathrm{B}$. A permutation was randomly assigned to every patient, so that the treatments were randomly assigned to the treatment areas.

Visits to the study site took place on day 1 (baseline), 8, and 15; the test areas were assessed prior to the application of each day's dose. A total clinical assessment score was determined for every patient, treatment, and visit as the sum of the individual severity of clinical symptoms of the SCORAD: erythema, edema/papulation, oozing/crusts, excoriations, lichenification, dryness, and itching. The severity of lesions was scored on a 4-point scale from 0 (= no symptoms) to 3 (= severe symptoms).

Corneometry was performed to quantify the stratum corneum hydration as a further measure of the treatment efficacy. At each visit, hydration was assessed perilesionally within each treatment area in a predefined and marked treatment area with a Corneometer CM 825 (Courage and Khazaka electronic, Cologne, Germany).

The assessment of stratum corneum hydration by corneometry was evaluated descriptively by treatment and visit, providing descriptive statistics for the absolute values, for the changes from baseline, and for differences in changes from baseline between the two treatments. In addition to the standard descriptive statistics, the $95 \%$ confidence intervals of the mean are provided.

The rate of efficient skin penetration, as a relevant cosmetic property, was estimated following the patients' recorded answers to the question 'has the test product been absorbed enough so that you would put on clothes again?', asked 15, 30, 45, and 60 min after the first application (study day 1).

Patients' satisfaction was assessed by a questionnaire on cosmetic properties and patients' satisfaction, which the participants completed at baseline and at the end of treatment. The rating was done on a 5-point scale (completely applicable, extensively applicable, somehow applicable, less applicable, and not applicable).

Health-related quality of life was recorded using the DLQI.

The overall assessment of the test preparations was based on the clinical evaluation (SCORAD), the stratum corneum hydration, the patients' statements on skin penetration, and the answers in the questionnaires on cosmetic properties and on quality of life.

Safety was evaluated on the basis of medical history and physical examination. Vital signs (blood pressure and pulse rate) were assessed on day 1 and on the last study day. Adverse events were recorded according to the physicians' observations and the patients' reports. 
Data Analysis and Statistics

Since the data were analyzed exploratively and interpreted in a non-confirmatory mode, no formal hypothesis had been postulated. Evaluation of trends and identification of differences in efficacy were made by means of descriptive statistics. Statistical evaluation was made using the SAS software package. Analyses of the intent-to-treat (ITT) population and of the per protocol (PP) population are provided for efficacy parameters (local SCORAD and corneometry). The analysis of the cosmetic assessment and DLQI was limited to the PP population. The total clinical assessment was determined as the sum of the individual clinical symptom score (total symptom score, TSS) of the SCORAD intensity scale. Results are given as mean values $\pm \mathrm{SD}$.

Comparisons between treatments were performed applying the sign test as distribution free and robust procedure.

Outcomes of the 10 questions of the questionnaire on quality of life (DLQI) surveyed on day 1 (baseline) and 15 (end of study) are presented by frequency tables (appendix 1) as the sum of the 10 scores. Descriptive statistics are provided for the DLQI and the derived item-specific scores for both visits, as well as for their changes from baseline.

\section{Results}

\section{Baseline Data}

Twenty patients with mild to moderate AE, 10 males and 10 females, all Caucasians, were included and valid for analyses. All patients performed all treatments as planned and documented in their diaries. The number of patients was identical for the safety, ITT, and PP population.

At baseline, the size of the treatment areas, the severity of lesions, skin hydration, and itching were comparable for both treatments.

At baseline, the defined test areas to be treated were comparable regarding

- the mean size of the treatment areas (175.5 and 175.3 $\mathrm{cm}^{2}$ for preparation 1 and 2 , respectively);

- the severity of lesions as evaluated by clinical assessment (SCORAD intensity criteria) with generally moderate erythema, edema/papulation, lichenification, dryness, and itching (median $=2$, each), mild excoriations $($ median $=1)$, rare oozing/crusts (median = 0 ), and TSS (median $=10.5$ and 11 for preparation 1 and 2, respectively);

- skin hydration as assessed by corneometry (mean 12.9 \pm 5.76 and $13.1 \pm 4.54$ for preparation 1 and 2 , respectively);

- itching assessed by the first question of the questionnaire (concerning 'the cosmetic properties and patients' satisfaction with the product') showing moderate itching in $60 \%$ of the patients (12 out of 20 ).

\section{Efficacy}

At the end of the study period, both treatments resulted in improvement of the skin condition, as measured by the TSS, the intensity of erythema, edema/papulation, dryness, itching score and skin hydration, and had beneficial effects on the patients' satisfaction.

After the first week of treatment, the mean TSS declined from $11.0 \pm 1.93$ to $4.3 \pm 2.58$ for preparation 1 and from $10.4 \pm 1.79$ to $3.6 \pm 2.39$ for preparation 2 (comparator). The second treatment week added further improvement with mean end-of-study TSS values of 2.6 \pm 1.76 for preparation 1 and $2.5 \pm 1.76$ for preparation 2. After the entire treatment period, mean TSS change from baseline was $-8.4 \pm 1.82$ in the lesion areas treated with preparation 1 , the newly developed formulation, and $-8.0 \pm 1.64$ in the areas treated with preparation 2 , the comparator. The median TSS change from baseline was -8.5 for preparation 1 and -8.0 for preparation 2 at day 15. The results were identical for the ITT and the PP analysis.

The statistical comparison did not reveal significant differences in the mean change from baseline of the TSS at day 8 and 15 .

All individual symptoms of the clinical score showed similar improvement, reflecting the reduction of the TSS. A slight difference between the treatments could be observed in the reduction of erythema: after 2 weeks of treatment, more lesional areas treated with preparation 2 than with preparation 1 were completely free of erythema $(65 \%, \mathrm{n}=13$, compared to $50 \%, \mathrm{n}=10)$.

The mean TSS, severity of individual symptoms, and the percentage of patients showing complete absence (score 0 ) of the respective symptom on day 15 are presented in table $1 \mathrm{a}, \mathrm{b}$.

\section{Corneometry}

The corneometry results (arbitrary units) showed considerable increase in skin moisturization with both preparations. The improvement of skin hydration was most pronounced in the first week for both preparations, where the mean values increased for preparation 1 from $12.9 \pm 5.79$ to $22.7 \pm 7.91$ and from $13.1 \pm 4.54$ to 20.8 \pm 6.90 for preparation 2 , but remained perceptible during the next week of treatment (table 2; fig. 1). The statistical comparison of the intraindividual outcomes did not show significant differences between the treatments comparing mean corneometric values at baseline with day 8 and 15 . 
Table 1. Severity of symptoms at baseline and after 1 and 2 weeks of treatment

a With preparation 1

\begin{tabular}{lcccc}
\hline & \multicolumn{2}{l}{ Preparation 1} & & \\
\cline { 2 - 5 } & baseline & day 8 & day 15 & day 15 score 0 \\
\hline Erythema & $2.2 \pm 0.37$ & $0.8 \pm 0.72$ & $0.6 \pm 0.60$ & $50(\mathrm{n}=10)$ \\
Edema/papulation & $1.7 \pm 0.57$ & $0.6 \pm 0.60$ & $0.3 \pm 0.55$ & $80(\mathrm{n}=16)$ \\
Oozing/crusts & $0.2 \pm 0.37$ & 0.0 & 0.0 & $100(\mathrm{n}=20)$ \\
Excoriations & $1.5 \pm 0.51$ & $0.3 \pm 0.44$ & 0.0 & $100(\mathrm{n}=20)$ \\
Lichenification & $1.9 \pm 0.72$ & $1.6 \pm 0.76$ & $1.3 \pm 0.64$ & $10(\mathrm{n}=2)$ \\
Dryness & $1.8 \pm 0.77$ & $0.9 \pm 0.59$ & $0.4 \pm 0.60$ & $65(\mathrm{n}=13)$ \\
Itching & $1.8 \pm 0.77$ & $0.4 \pm 0.49$ & $0.1 \pm 0.31$ & $90(\mathrm{n}=18)$ \\
TTS & $11.0 \pm 1.93$ & $4.3 \pm 2.58$ & $2.6 \pm 1.76$ & \\
TTS reduction from baseline & & $-6.7 \pm 2.21$ & $-8.4 \pm 1.82$ & \\
\hline
\end{tabular}

b With preparation 2

\begin{tabular}{lcccc}
\hline & \multicolumn{2}{l}{ Preparation 2, comparator } & & \\
\cline { 2 - 4 } & baseline & day 8 & day 15 & day 15 score 0 \\
\hline Erythema & $2.1 \pm 0.31$ & $0.6 \pm 0.68$ & $0.4 \pm 0.60$ & $65(\mathrm{n}=13)$ \\
Edema/papulation & $1.6 \pm 0.60$ & $0.5 \pm 0.69$ & $0.3 \pm 0.57$ & $75(\mathrm{n}=15)$ \\
Oozing/crusts & $0.1 \pm 0.22$ & 0.0 & 0.0 & $100(\mathrm{n}=20)$ \\
Excoriations & $1.5 \pm 0.51$ & $0.1 \pm 0.31$ & 0.0 & $100(\mathrm{n}=20)$ \\
Lichenification & $1.9 \pm 0.64$ & $1.4 \pm 0.82$ & $1.3 \pm 0.64$ & $10(\mathrm{n}=2)$ \\
Dryness & $1.8 \pm 0.70$ & $0.8 \pm 0.55$ & $0.5 \pm 0.60$ & $60(\mathrm{n}=12)$ \\
Itching & $1.6 \pm 0.60$ & $0.3 \pm 0.44$ & $0.1 \pm 0.22$ & $95(\mathrm{n}=19)$ \\
TTS & $10.4 \pm 1.79$ & $3.6 \pm 2.39$ & $2.5 \pm 1.76$ & \\
TTS reduction from baseline & & $-6.9 \pm 1.87$ & $-8.0 \pm 1.64$ & \\
\hline
\end{tabular}

Score 0 represents complete absence of the respective symptom in percentage (number of patients).

Questionnaire Statements regarding Cosmetic

Properties and Patients' Satisfaction

The patients' acceptance of and satisfaction with the two mometasone preparations (questionnaire, see appendix 1) were generally good for both preparations as documented in the questionnaire. Significant differences favoring the newly developed mometasone cream were found for the following questions (table 3):

- Judgment of daily application: the statement 'the cream is convenient for daily application' was considered as completely applicable by $70 \%(n=14)$ of judgments for preparation 1 and $40 \%(\mathrm{n}=8)$ for preparation $2(\mathrm{p}=0.0391)$.

- Time of permeation: rapid permeation was attributed to preparation 1 by 10 out of 20 and to preparation 2 by 2 out of 20 patients ( 50 vs. $10 \%, p=0.0063$ ).
- Individual preference: 15 out of 20 patients preferred the newly developed cream (preparation 1) over the comparator (preparation 2), and 5 out of 20 did not (75 vs. $25 \%, \mathrm{p}=0.0414)$.

A difference that was near statistical significance was found for ease and convenience of application and for the spreadability of the preparation:

- The statement 'the application of the cream is easy and convenient' was tagged as completely applicable by 18 out of 20 judgments on preparation 1 and by 13 out of 20 for preparation 2 ( 90 vs. $65 \%, \mathrm{p}=0.0625$ ).

- The statement 'the cream is easy to spread' was rated completely applicable by 12 out of 20 patients for preparation 1 and by 4 out of 20 patients for preparation 2 ( 60 vs. $20 \%, p=0.0574$ ).

All other questions or statements produced comparable rating profiles. 
Table 2. Results of corneometry after 1 and 2 weeks of treatment with preparations 1 and 2

\begin{tabular}{|c|c|c|c|c|c|c|}
\hline & \multicolumn{3}{|c|}{ Preparation 1} & \multicolumn{3}{|c|}{ Preparation 2} \\
\hline & baseline & day 8 & day 15 & baseline & day 8 & day 15 \\
\hline \multicolumn{7}{|l|}{ Corneometry } \\
\hline Mean & $12.9 \pm 5.79$ & $22.7 \pm 7.91$ & $25.8 \pm 7.29$ & $13.1 \pm 4.54$ & $20.8 \pm 6.90$ & $24.0 \pm 8.34$ \\
\hline Median & 11.4 & 21.3 & 24.3 & 14.1 & 21.8 & 22.0 \\
\hline Mean change from baseline & & $+9.9 \pm 5.38$ & $+12.9 \pm 5.81$ & & $+7.7 \pm 5.17$ & $+10.9 \pm 6.56$ \\
\hline
\end{tabular}

Table 3. Statements revealing superiority of the newly developed mometasone cream (preparation 1)

\begin{tabular}{llll}
\hline Statement (completely applicable) & Preparation 1 & Preparation 2 & p value \\
\hline The application of the cream is easy and convenient & $90(\mathrm{n}=18)$ & $65(\mathrm{n}=13)$ & 0.0625 \\
The cream is convenient for daily application & $70(\mathrm{n}=14)$ & $40(\mathrm{n}=8)$ & 0.0391 \\
The cream permeates quickly & $50(\mathrm{n}=10)$ & $10(\mathrm{n}=2)$ & 0.0063 \\
The cream is easy to spread & $60(\mathrm{n}=12)$ & $20(\mathrm{n}=4)$ & 0.0574 \\
I prefer the cream & $75(\mathrm{n}=15)$ & $25(\mathrm{n}=5)$ & 0.0414 \\
\hline
\end{tabular}

Data are expressed as percentage (number of patients).

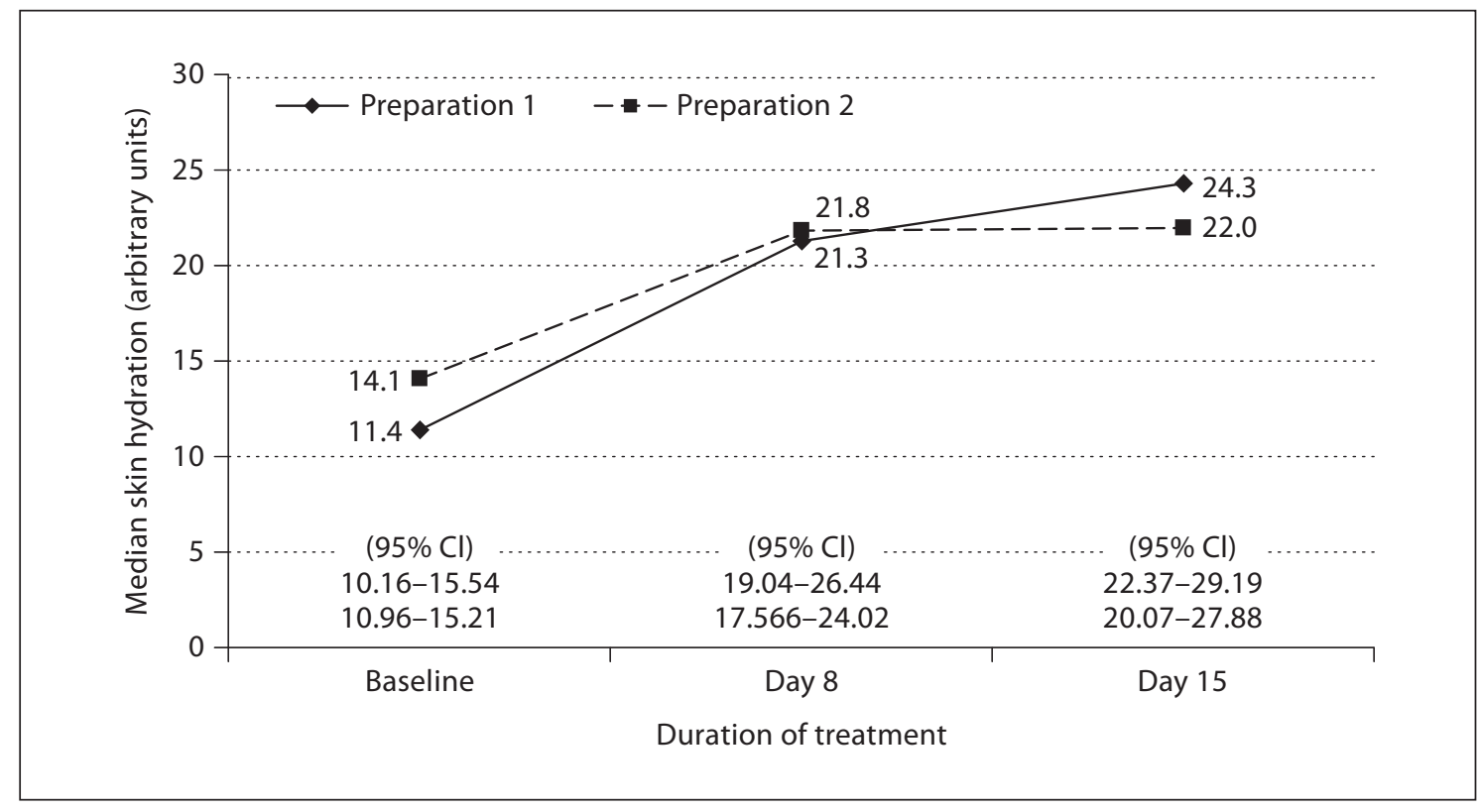

Fig. 1. Improvement of skin hydration measured by corneometry (median) after 1 and 2 weeks of treatment with preparations 1 and 2 . 


\section{Skin Penetration}

Preparation 1 was rated as sufficiently absorbed at the following time points: $15 \mathrm{~min}$ after application by 2 of 20 patients (10.0\%), 30 min after application in half of the patients (50\%), and 45 and $60 \mathrm{~min}$ after application in 4 patients (20\%). The respective results for preparation 2 are: $15 \mathrm{~min}$ after application in 4 patients $(20.0 \%), 30 \mathrm{~min}$ after application in 3 patients (15.0\%), 45 min after application in 8 patients (40.0\%), and $60 \mathrm{~min}$ after application in 5 patients $(25.0 \%)$. Thirty minutes after application, $60 \%(n=12)$ of patients treated with preparation 1 rated penetration to be sufficient to put clothes on compared to $35 \%$ of patients $(n=7)$ treated with preparation 2 (PP analysis). With a p value of 0.0625 , the difference missed significance, but indicated a tendency.

\section{Improvement of Quality of Life}

The data derived from the questionnaire on quality of life (DLQI, appendix 2) indicate considerable improvement in patients' quality of life during the study period. The mean index decreased from $8.5 \pm 5.2$ at baseline to $3.0 \pm 3.3$ at day 15 (corresponding median values 7.0 and 2.0 , respectively), showing that the initially moderate impact of the dermatological condition was reduced to a lower degree (median change from baseline -3.5).

Six subscores of the DLQI, regarding symptoms and feelings (questions 1 and 2), daily activities (questions 3 and 4), leisure (questions 5 and 6), work and school (question 7), personal relationships (questions 8 and 9), and treatment (question 10), had been evaluated separately and showed improvement during the study period as clearly as the total index did.

The improvement of symptoms and feelings showed a median decrease of 2.0 score points from baseline. Symptoms like itching, sore, pain, or stinging were absent in $50 \%$ of the patients $(\mathrm{n}=10)$ and were assessed as mild by most of the remaining patients. In $65 \%$ of the patients $(\mathrm{n}=13)$, no embarrassment or compromised self-consciousness due to the skin condition was noted at the end of the study period. The majority of the patients $(65.0 \%$, $n=13$ ) reported that their skin condition did not interfere with their everyday activities. No influence of skin on the choice of clothes was noted in the majority of patients $(70.0 \%, \mathrm{n}=14)$. During the study period, a slight improvement was seen concerning leisure and social activities. The majority of patients declared that their skin did not affect any social or leisure $(80.0 \%, \mathrm{n}=15)$ or sports activities $(65.0 \%, \mathrm{n}=13)$. A slight improvement was also observed regarding the attendance of work and school during the study period. All 20 patients reported that their skin condition did not prevent them from working or studying, and most of the patients $(75.0 \%, \mathrm{n}=15)$ found that their skin had not been a problem at work or while studying. No relevant changes were noted in personal relationships. The majority of patients $(85.0 \%, \mathrm{n}=$ 17) reported no problems with their partners or any of their close friends or relatives due to their skin and most of the patients $(70.0 \%, \mathrm{n}=14)$ noted no sexual difficulties caused by their skin. Most of the patients $(75.0 \%, \mathrm{n}=15)$ did not report any problems with the treatment of their skin. For detailed outcomes of the DLQI, see appendix 2.

\section{Safety}

There were no adverse events reported in this trial. The final physical examination did not show abnormal findings in any of the patients. The investigators had considered all vital signs in an acceptable range. Slight changes in systolic and diastolic blood pressure and heart rate between baseline and final visit were clinically not relevant. Overall, this trial did not raise any safety concerns.

\section{Discussion}

The development of new corticosteroids and respective formulations for topical application from the late 1980s until today has targeted a better benefit/risk ratio. Mometasone furoate, one of these new derivatives [8], is characterized by persistent high intradermal concentrations and very low systemic availability [3]. Mometasone furoate is categorized as a class III topical corticosteroid, and its atrophogenic potential was found to be low $[6,9]$. Consequently, a therapeutic index of 2.0 has been attributed to this glucocorticoid [3].

The overall treatment success does not only depend on the risk-benefit profile of the active ingredient. It may be supported or compromised by factors beyond the established substance profile. Because excipients such as penetration enhancers may add to efficacy and tolerability [10], two glucocorticoid preparations with the same active ingredient are not necessarily interchangeable. Therefore, any new formulation requires the confirmation of its clinical equivalence to the originator preparation prior to its approval as a medicinal product, even if its active ingredient is well established and approved as a therapeutic agent in other topical preparations.

A nother aspect of the formulation refers to the cosmetic properties and the ease of use: the regularity of application is crucial for patients suffering from chronic 
skin conditions such as $\mathrm{AE}$, and the patients' adherence to treatment is better if a convenient and user-friendly preparation with good properties to spread and rapid penetration is provided. A medicinal product that is not accepted for cosmetic reasons tends to compromise the treatment adherence and treatment success.

Ointments are sometimes considered to be of higher potency than creams containing the same concentration of the active ingredient, probably due to their occlusive effect which is supposed to enhance drug penetration by increasing hydration of the stratum corneum $[2,11]$. Contradictory findings have been published by Korting et al. [12] in 2005, suggesting similar efficacy for cream and ointment when the content of the respective glucocorticoid is the same.

The therapeutic equivalence of the new mometasone formulation and the commercially available product has been described earlier on the basis of a vasoconstriction test and a psoriasis plaque test [13].

In the study reported here, the equivalence of the newly developed cream with a higher water content in an $\mathrm{O} / \mathrm{W}$ emulsion with a well-established fatty cream used in AE patients could be confirmed. Its good moisturizing effect was not only shown by corneometry results, but is consistent with the improvement in skin dryness. In 65\% $(n=13)$ of lesion areas treated by the new formulation (preparation 1$)$ and $60 \%(n=12)$ of lesion areas treated by preparation 2 (comparator) the symptom dryness was completely absent (score 0 ) at the end of study. These results might challenge the assumption of a superior moisturizing effect of an ointment and support the priority of the convenience of use.

\section{Conclusion}

In terms of efficacy - assessed by the SCORAD score, the patients' evaluation of the skin condition, and corneometry measurements - the study data show that the newly developed mometasone cream formulation with a water content of $33 \%$ is equivalent to the commercially available fatty cream with the same content of $0.1 \%$ mometasone furoate in the treatment of AE. These results also confirm the bioequivalence of both mometasone furoate preparations shown earlier in clinical experimental settings [13].

The patient-reported acceptance of the new cream confirms the role of cosmetic properties and the importance of the ease of daily use of a topical preparation for the quality of life in patients with chronic skin disorders.

\section{Appendix}

Appendix 1

Questionnaire regarding cosmetic properties and patients' satisfaction with the product:

Part 1: Questions with answering options: completely applicable, widely applicable, somehow applicable, less applicable, and not applicable:

- The application of the cream is easy and convenient.

- The cream is convenient for daily application.

- The cream permeates quickly.

- The cream is well spreadable.

- The cream is suitable for the application on inflamed and sensitive skin.

- I like the application of this cream more than the treatment I used before.

Part 2

\begin{tabular}{ll}
\hline Question & Answering options \\
\hline $\begin{array}{l}\text { Visible effect } \\
\text { The first effect was visible after }\end{array}$ & $\begin{array}{l}\text { yes/no } \\
\text { ? treatment days }\end{array}$ \\
\hline $\begin{array}{l}\text { How has your skin condition im- } \\
\text { proved? }\end{array}$ & $\begin{array}{l}\text { completely/visibly/slightly/ } \\
\text { no difference/worse }\end{array}$ \\
$\begin{array}{l}\text { How do you assess the tolerability } \\
\text { of the creams? }\end{array}$ & $\begin{array}{l}\text { very good/good/satisfying/ } \\
\text { sufficient/poor }\end{array}$ \\
\hline $\begin{array}{l}\text { How do you assess the itching } \\
\text { of your skin after repeated } \\
\text { application? }\end{array}$ & $\begin{array}{l}\text { severe/strong/moderate/ } \\
\text { slight/no itching }\end{array}$ \\
$\begin{array}{l}\text { I prefer cream } \\
\text { (Please tick only one cream) }\end{array}$ & A or B \\
\hline $\begin{array}{l}\text { I would recommend the cream to } \\
\text { other patients }\end{array}$ & yes/no \\
\hline
\end{tabular}

Appendix 2

Questionnaire on quality of life (DLQI):

\begin{tabular}{rr}
$\begin{array}{l}\text { Day 1 } \\
\%\end{array}$ & \multicolumn{1}{l}{$\begin{array}{l}\text { Day } 15 \\
\%\end{array}$} \\
\hline 25.0 & 0.0 \\
65.0 & 10.0 \\
10.0 & 40.0 \\
0.0 & 50.0 \\
\hline
\end{tabular}




\begin{tabular}{|c|c|c|c|c|c|c|c|}
\hline & & $\begin{array}{l}\text { Day } 1 \\
\%\end{array}$ & $\begin{array}{l}\text { Day } 15 \\
\%\end{array}$ & & & $\begin{array}{l}\text { Day } 1 \\
\%\end{array}$ & $\begin{array}{l}\text { Day } 15 \\
\%\end{array}$ \\
\hline \multirow{3}{*}{$\begin{array}{l}\text { Over the last week, how } \\
\text { embarrassed or self-conscious } \\
\text { have you been because of your } \\
\text { skin? }\end{array}$} & Very much & 5.0 & 0.0 & \multirow{2}{*}{$\begin{array}{l}\text { Over the last week, has your skin } \\
\text { prevented you from working or } \\
\text { studying? }\end{array}$} & Yes & 0.0 & 0.0 \\
\hline & A little & 70.0 & 35.0 & & Not relevant & 0.0 & 0.0 \\
\hline & Not at all & 10.0 & 65.0 & \multirow{2}{*}{$\begin{array}{l}\text { If 'No', over the last week, how } \\
\text { much has your skin been a } \\
\text { problem at work or studying? }\end{array}$} & A lot & 15.0 & 0.0 \\
\hline \multirow{4}{*}{$\begin{array}{l}\text { Over the last week, how much has } \\
\text { your skin interfered with you } \\
\text { going shopping or looking after } \\
\text { your home or garden? }\end{array}$} & Very much & 0.0 & 0.0 & & A little & 40.0 & 25.0 \\
\hline & A little & 40.0 & 35.0 & \multirow{5}{*}{$\begin{array}{l}\text { Over the last week, how much has } \\
\text { your skin created problems with } \\
\text { your partner or any of your close } \\
\text { friends or relatives? }\end{array}$} & Very much & 5.0 & 0.0 \\
\hline & $\begin{array}{l}\text { Not at all } \\
\text { Not relevant }\end{array}$ & $\begin{array}{r}50.0 \\
+\quad 0.0\end{array}$ & $\begin{array}{r}65.0 \\
0.0\end{array}$ & & A lot & 5.0 & 0.0 \\
\hline & & & & & A little & 20.0 & 15.0 \\
\hline \multirow{2}{*}{$\begin{array}{l}\text { Over the last week, how much has } \\
\text { your skin influenced the clothes } \\
\text { you wear? }\end{array}$} & Very much & 20.0 & 5.0 & & Not at all & 70.0 & 85.0 \\
\hline & A lot & 5.0 & 10.0 & & Not relevant & 0.0 & 0.0 \\
\hline \multirow{4}{*}{$\begin{array}{l}\text { Over the last week, how much has } \\
\text { your skin affected any social or } \\
\text { leisure activities? }\end{array}$} & A lot & 5.0 & 0.0 & $\begin{array}{l}\text { Over the last week, how much has } \\
\text { your skin caused any sexual } \\
\text { difficulties? }\end{array}$ & Not relevant & 15.0 & 15.0 \\
\hline & A little & 30.0 & 15.0 & \multirow{8}{*}{$\begin{array}{l}\text { Over the last week, how much of } \\
\text { a problem has the treatment of } \\
\text { your skin been, for example by } \\
\text { making your home messy or by } \\
\text { taking up time? }\end{array}$} & Very much & 5.0 & 0.0 \\
\hline & Not at all & 55.0 & 80.0 & & A lot & $\begin{array}{l}5.0 \\
5.0\end{array}$ & $\begin{array}{l}0.0 \\
0.0\end{array}$ \\
\hline & Not relevant & 0.0 & 5.0 & & A little & 45.0 & 25.0 \\
\hline Over the last week, how much has & Very much & 10.0 & 5.0 & & Not at all & 35.0 & 75.0 \\
\hline your skin made it difficult for you & A lot & 0.0 & 0.0 & & Not relevant & 10.0 & 0.0 \\
\hline \multirow[t]{3}{*}{ to do any sport? } & A little & 25.0 & 10.0 & & & & \\
\hline & Not at all & 50.0 & 65.0 & & & & \\
\hline & Not relevant & 15.0 & 20.0 & & & & \\
\hline
\end{tabular}

\section{References}

$\checkmark 1$ Darsow U, Lubbe J, Taieb A, Seidenari S, Wollenberg A, Calza AM, et al: Position paper on diagnosis and treatment of atopic dermatitis. J Eur Acad Dermatol Venereol 2005; 19:286-295.

2 Peterson JD, Chan LS: A comprehensive management guide for atopic dermatitis: topical therapy. Dermatol Nurs 2006;18:531542.

3 Luger TA: Topische Dermatotherapie mit Glukokortikoiden; in Korting HC, Callies R, Reusch M, Schlaeger M. Sterry W (eds): Dermatologische Qualitätssicherung. Leitlinien und Empfehlungen. Berlin, ABW Wissenschaftsverlag, 2009, pp 943-951.

$\checkmark 4$ Prakash A, Benfield P: Topical mometasone. A review of its pharmacological properties and therapeutic use in the treatment of dermatological disorders. Drugs 1998;55:145-163.

$>5$ Kulhalli P, Chevli T, Karnik R, Sheth M, Mulgaonkar N: Comparative potency of formulations of mometasone furoate in terms of inhibition of 'PIRHR' in the forearm skin of normal human subjects measured with laser Doppler velocimetry. Indian J Dermatol Venereol Leprol 2005;71:170-174.

6 Kerscher MJ, Hart H, Korting HC, Stalleicken D: In vivo assessment of the atrophogenic potency of mometasone furoate, a newly developed chlorinated potent topical glucocorticoid as compared to other topical glucocorticoids old and new. Int J Clin Pharmacol Ther 1995;33:187-189.

7 Kirkland R, Pearce DJ, Balkrishnan R, Feldman SR: Critical factors determining the potency of topical corticosteroids. J Dermatol Treat 2006;17:133-135.

$>8$ Koivukangas V, Karvonen J, Risteli J, Oikarinen A: Topical mometasone furoate and betamethasone-17-valerate decrease collagen synthesis to a similar extent in human skin in vivo. Br J Dermatol 1995;132:66-68.

$>9$ Hoffmann K, Auer T, Stücker M, Hofmann A, Altmeyer P: Comparison of skin atrophy and vasoconstriction due to mometasone furoate, methylprednisolone and hydrocorti- sone. J Eur Acad Dermatol Venereol 1998;10: 137-142.

10 Faergemann J, Christensen O, Sjövall P, Johnssson A, Hersle K, Nordin P, Edmar B, Svensson A: An open study of efficacy and safety of long-term treatment with mometasone furoate fatty cream in the treatment of adult patients with atopic dermatitis. J Eur Acad Dermatol Venereol 2000;14:393-396.

11 Brazzini B, Pimpinelli N: New and established topical corticosteroids in dermatology. Am J Clin Dermatol 2002;3:47-58.

$\checkmark 12$ Korting HC, Maslen K, Gross G, Willers C: Vergleich der Wirksamkeit verschiedener topischer Glukokortikoidcremes und -salben im Vasokonstriktionstest: Überlegenheit von Hydrocortisonbutyrat gegenüber Hydrocortison. J Dtsch Dermatol Ges 2005;3:348-353.

13 Korting HC, Schöllmann C, Willers C, Wigger-Alberti W: Bioavailability, antipsoriatic efficacy and tolerability of a new light cream with mometasone furoate $0.1 \%$. Skin Pharmacol Physiol 2012;25:133-141. 